\title{
OCORRÊNCIA DE AEROMONAS SPP. EM ABATEDOURO BOVINO E SENSIBILIDADE A ANTIMICROBIANOS
}

\section{T.M. Martineli, O.D. Rossi Junior, N.D. Cereser, M.V. Cardozo, B.A. Kamimura, N.M. Nespolo, F.R. Pinto}

Universidade Estadual Paulista “Júlio de Mesquita Filho", Faculdade de Ciências Agrárias e Veterinárias, Departamento de Medicina Veterinária Preventiva e Reprodução Animal, Via de Acesso Prof. Paulo Donato Castellane s/no, CEP 14884-900, Jaboticabal, SP, Brasil. E-mail: thaismartineli@yahoo.com

\section{RESUMO}

O gênero Aeromonas compreende espécies consideradas importantes patógenos para os seres humanos, sendo as gastroenterites as infecções mais comumente atribuídas a estas bactérias. Tendo em vista sua importância como patógeno de origem alimentar, a ocorrência deAeromonas spp. foi estudada em carcaças bovinas e ambiente do abatedouro em uma indústria do Estado deSão Paulo. Foram colhidas 285 amostras de 19 locais. Foi realizada a contagem direta por semeadura em meio seletivo, caracterização bioquímica das espécies após enriquecimento seletivo e teste de sensibilidade a antimicrobianos. A contagem direta permitiu a quantificação dessas bactérias em apenas 12 amostras, variando de 0,5 a $9,2 \times 10^{\circ} \mathrm{UFC} / \mathrm{cm}^{2}$, sendo cinco delas de ambiente, com populações que variaram de $1,0 \times 10^{\circ}$ a 3,0 × $10^{\circ} \mathrm{UFC} /$ placa. Entretanto, após o enriquecimento seletivo, Aeromonas spp. foram isoladas de 38 amostras que, somadas às amostras de ambiente não submetidas ao enriquecimento, forneceram 62 isolados para análise. A caracterização bioquímica das espécies permitiu verificar a ocorrência de 59 isolados de $A$. caviae, um de $A$. sobria, um de $A$. trota e um de $A$. schubertii. O teste com antimicrobianos revelou resistência de todos os isolados pela ampicilina e cefalotina, enquanto, para os demais antimicrobianos, esta foi variável. A resistência da totalidade dos isolados a determinados antimicrobianos indica que estes devem ser utilizados criteriosamente com a finalidade de evitar o surgimento precoce de cepas deAeromonas spp. multirresistentes. Ainda, a maior prevalência de A.caviae deve ser considerada relevante, pois trata-se de uma das espécies causadoras de gastroenterite em humanos.

PALAVRAS-CHAVE: Aeromonas spp., sensibilidade antimicrobiana, abatedouro bovino.

\section{ABSTRACT}

OCCURRENCE OF AEROMONAS SPP. IN BOVINE ABATTOIR AND ANTIMICROBIAL SENSITIVITY. The genus Aeromonas comprises important human pathogens, gastroenteritis being the most common type of infection attributed to these bacteria. Considering their importance as foodborne pathogens, the occurrence of Aeromonas spp. was studied on bovine carcasses and the environment of a slaughterhouse in São Paulo State, Brazil. A total of 285 samples were collected from 19 points. Direct counting was carried out by seeding on selective medium, with biochemical characterization of the species after selective enrichment and antimicrobial sensitivity testing. The direct count permitted bacteria quantification only in 12 samples ranging from 0.5 to $9.2 \times 10^{\circ} \mathrm{CFU} /$ $\mathrm{cm}^{2}$, of which 5 were from environment, ranging from $1.0 \times 10^{0}$ to $3.0 \times 10^{\circ} \mathrm{CFU} /$ plate. However, after selective enrichment, Aeromonas spp. was isolated from 38 samples, which when added to the environmental samples not subjected to the enrichment provided 62 isolates for analysis. Biochemical characterization allowed for the verification of the occurrence of 59 isolates of $A$. caviae, 1 of $A$. sobria, 1 of $A$. trota and 1 of $A$. schubertii. Antimicrobial testing revealed that all isolates were resistant to ampicillin and cephalotin, while the results for the other antimicrobials were variable. Resistance of all isolates to some antimicrobials indicates that these must be used carefully to avoid early development of multiresistant Aeromonas spp. Also, the greatest prevalence of $A$. caviae must be considered relevant because it is one of the causative species of human gastroenteritis.

KEY WORDS: Aeromonas spp., antimicrobial sensitivity, bovine abattoir. 


\section{INTRODUÇÃO}

O gênero Aeromonas compreende espécies já isoladas de vários alimentos e que têm sido consideradas importantes patógenos para os seres humanos, atuando tanto como agentes infecciosos como enterotoxigênicos (UlLMANN et al., 2005).

Várias espécies de aeromonas são consideradas importantes patógenos para os seres humanos causando infecções extraintestinais em pessoas imunocomprometidas ou não (Аввотт et al., 2003). A principal ação patogênica das Aeromonas spp. corresponde às gastroenterites, podendo ocorrer diarreia nas formas secretória (aquosa, geralmente com vômito), disentérica, crônica (persistente por mais de 10 dias), colérica e dos viajantes com diferentes características (GRAVAENITZ, 2007). A população mais frequentemente afetada por gastroenterite causada por Aeromonas spp. inclui crianças, idosos e pessoas imunossuprimidas por medicamentos ou doenças (SubASHKUMAR et al., 2006).

As três espécies de aeromonas mesofílicas consideradas mais importantes e causadoras de várias enfermidades em humanos sãoA. hydrophila, A.veronii biovar sobria e $A$. caviae que correspondem a $85 \%$ de todos os isolados clínicos envolvidos em infecções gastrointestinais e extraintestinais (DASKALOV, 2006).

Os produtos alimentícios de onde têm sido frequentemente isoladas incluem o pescado, vegetais, carnes vermelhas e leite cru entre outros (MERINo etal., 1995), sendo de grande importância naqueles armazenados sob refrigeração, pois algumas Aeromonas spp. podem se multiplicar sob essas temperaturas (KIROV, 1997). A. hydrophila apresenta capacidade de se multiplicar em uma grande variedade de produtos embalados a vácuo e armazenados entre $-2 \mathrm{e} 10^{\circ} \mathrm{C}$, tais como a carne bovina (GILL;REICHEL, 1989), carne assada (HUdson et al., 1994), carne suína (LAACK et al.,1993) e carne ovina (DoherTy et al., 1996). Segundo KIROv; BRodribB (1993), cepas de Aeromonas spp. podem produzir enterotoxinas nos alimentos armazenados sob baixas temperaturas $\left(7^{\circ} \mathrm{C}\right)$.

A sensibilidade das cepas de Aeromonas spp., provenientes de casos clínicos, aos antimicrobianos tem sido estudada com frequência (PALú et al., 2006; GUERRA et al., 2007; AlCAIDE et al., 2010). No entanto, o conhecimento sobre as cepas de origem ambiental e originárias da carne bovina e ambiente de abate é pequeno, principalmente no Brasil.

Face ao exposto e à importância da carne bovina e seus produtos na alimentação da população, no potencial risco das Aeromonas spp. desencadearem processos gastrointestinais patológicos e, ainda, na utilização inadequada de antimicrobianos na medicina humana, que tem elevado a resistência destas bactérias, idealizou-se o presente estudo, objetivando- se avaliar a ocorrência e quantificar Aeromonas spp. em carcaças bovinas e ambiente do abatedouro, assim como verificar o comportamento destas bactérias em relação a antimicrobianos.

\section{MATERIAL E MÉTODOS}

\section{Amostragem}

As amostras foram colhidas em um abatedouro do interior de São Paulo em dias normais de trabalho. Foram colhidas amostras em 19 pontos na linha de abate bovino, compreendendo desde a chegada dos animais para abate (pele seca) até a carne pronta para comercialização. Assim, em um primeiro dia foi amostrada a pele. No segundo, após os animais terem sido submetidos ao descanso, jejum e dieta e estarem preparados para o abate, foi amostrada a superfície da pele úmida das regiões dianteira e traseira e, no transcorrer do abate, foram amostradas a superfície muscular das regiões dianteira e traseira durante a fase de toalete, superfície de mãos de manipuladores (antes do início e durante as atividades) e superfície de facas na sala de matança, água tratada de abastecimento eágua residuária da lavagem das carcaças, colhida em frascos de vidro estéreis, em seguida à lavagem das meias carcaçasquandooexcesso dessaágua escorreaolongo dasfaces externa einterna. Além disso, no segundodia colhia-se amostras do ambiente da sala de abate, expondo-se por 15 minutos placas de Petri contendo os meios seletivos específicos para o gênero em estudo (ágar dextrina-ampicilina e ágar vermelho de fenolamido-ampicilina) e conteúdo intestinal, na seção de bucharia e triparia no momento da abertura do aparelho digestivo para sua a lavagem e preparação. No terceiro dia foram colhidas amostras de superfície muscular das regiões dianteira e traseira da carcaça na câmara de resfriamento, superfície das mãos dos manipuladores da câmara de resfriamento durante suas atividades, da parede, piso e ralo da própria câmara e carne pronta para comercialização obtida na sala de desossa. Analisou-se também a água sem tratamento (não clorada) proveniente de poço artesiano do próprio estabelecimento. De cada um dos pontos descritos foram analisadas 15 amostras, totalizando 285 unidades. As amostras de água tratada e sem tratamento foram colhidas em frascos de vidro esterilizados contendo $0,4 \mathrm{~mL}$ de tiossulfato de sódio em solução a $10 \%$, em quantidade aproximada de $400 \mathrm{~mL}$. As amostras de superfície de pele, músculos, parede, piso e ralo foram colhidas através de suabes esterilizados, em uma área de $100 \mathrm{~cm}^{2}$ delimitada por um gabarito deaçoinoxidávelestéril, queforam colocados em tubos de ensaio contendo quatro mililitros de água peptonada a $0,1 \%$. Para a colheita de material das facas 
e mãos, foi utilizado um suabe para cada amostra, sendo colhido de toda a superfície da lâmina da faca e espaços interdigitais e palma das mãos. Após a colheita, as amostras foram acondicionadas em caixa isotérmica contendogelorecicláveleencaminhadas ao Departamento de Medicina Veterinária Preventiva da FaculdadedeCiências Agráriase Veterinárias, Campus de Jaboticabal, Unesp, para a realização das análises.

\section{Contagem direta de Aeromonas spp.}

Para realização da contagem direta por semeadura em superfície, 0,1 mL de cada amostra foi semeado em placas de ágar vermelho de fenol-amido-ampicilina, as quais foram incubadas a $28^{\circ} \mathrm{C}$ por $24 \mathrm{~h}$. Todas as amostras de água e solução de transporte dos suabes foram inoculadas na sua condição original e diluídas a 1/10 emágua peptonada a 0,1\%. Para as amostras de carne e conteúdo intestinal foi utilizada diluição 1/10 na qual $25 \mathrm{~g}$ de cada um dos tipos de amostra foram homogeneizados, em aparelho Stomacher, com 225 $\mathrm{mL}$ de caldo tripticase soja (TSB) adicionado de ampicilina (30mg/L). Assim, nessecaso, foi inoculada somente essa diluição a $1 / 10$. Foram quantificadas as colônias amarelas, circundadas por halo transparente em decorrência da hidrólise do amido.

Enriquecimento seletivo e caracterização das espécies de Aeromonas spp.

O enriquecimento seletivo foi realizado em caldo TSB $\left(28^{\circ} \mathrm{C} / 24 \mathrm{~h}\right)$ e, para esta etapa, as amostras de água tratada e sem tratamento foram filtradas em membranas deéster de celulose ${ }^{*}$ de $47 \mathrm{~mL}$ de diâmetro e poros de 0,45 micrômetros, as quais foram picadas e colocados em $100 \mathrm{~mL}$ de TSB. Para as amostras de água residuária da lavagem das meias carcaças colocou-se $10 \mathrm{~mL}$ dela em $100 \mathrm{~mL}$ de TSB. Os suabes, bem como a água peptonada utilizada no transporte, após a retirada da alíquota utilizada na prova de semeadura direta para contagem, foram vertidos em tubos de ensaio contendo $20 \mathrm{~mL}$ de TSB. Após a incubação, foi realizado plaqueamento em ágar vermelho de fenolamido (PAlumboet al.,1985) eágar dextrina (HAvelaAR; VoNK, 1988), adicionados com ampicilina (10 mg/L) e incubação a $28^{\circ} \mathrm{C}$ por $24 \mathrm{~h}$.

Destes meios, bem como daquele usado na quantificação, foram selecionadas entre seis e oito colônias (isolados) sugestivas que, após serem caracterizadas como bastonetes Gram negativos, foram semeadas em ágar tríplice-açúcar-ferro (TSI) (SAAD et al., 1995) e, posteriormente, submetidas às provas da motilidade, oxidase, catalase e resistência ao agente vibriostático O/129 (fosfato de 2,4-diamino-6,7diisopropylpteridine) para determinação do gênero. A caracterização das espécies foi realizada seguindo o esquema proposto por POPOFF (1984) eFURUWATARI et al. (1994) complementado com provas adotadas por Авотт et al. (2003). Para esta caracterização, bem como para a realização dos testes de sensibilidade a antimicrobianos, foram selecionados 62 isolados abrangendo todos os locais amostrados.

Foram utilizadas como controle positivo para as provas bioquímicas as cepas dereferência: ATCC 43979 (A. veronii biotype sobria), ATCC 43700 (A. schubertii), ATCC 15468 (A. caviae) e ATCC 49657 (A. trota).

\section{Teste de sensibilidade a antimicrobianos}

O teste de sensibilidade a antimicrobianos foi realizado conforme o método de difusão de discos de antimicrobianos de Kirb-Bauer em ágar Muller-Hinton (Merck) (NCCLS, 1990). Os antimicrobianos utilizados foram amicacina, amoxicilina/clavulanato, ampicilina, cefalotina, cefepime, cefoxitina, ceftazidima, cefuroxima, ciprofloxacin, gentamicina, imipenem e sulfazotrim (Laborclin ${ }^{\circledR}$ ).

\section{RESULTADOS E DISCUSSÃO}

A quantificação foi possível em apenas 12 amostras, sendo o menor valor populacional de $0,5 \times 10^{0}$ $\mathrm{UFC} / \mathrm{cm}^{2}$ para uma amostra da superfície da pele úmida da região dianteira, para uma amostra da superfície muscular da região traseira da carcaça resfriada e para uma amostra da superfície muscular da região traseira durante a fase de toalete; uma amostra de mão durante o trabalho apresentou valor de $7,0 \times 10^{0} \mathrm{UFC} /$ mão e o maior valor populacional foi de $9,2 \times 10^{0} \mathrm{UFC} / \mathrm{cm}^{2}$ para uma amostra da superfície do piso e ralo da câmara de resfriamento. Para este último grupo de amostragem, ainda houve duas amostras com contagens de 1,2 e 3,2 x $10^{0} \mathrm{UFC} / \mathrm{cm}^{2}$.

Rossi Junioret al. (2006) determinaram a população de Aeromonas spp. em abatedouro bovino e também apresentaram um número reduzido de amostras em que foi possível realizar a contagem populacional dessas bactérias. Nas amostras de pele úmida da região traseira, esses autores encontraram populações variando entre $0,2 \times 10^{1}$ e $1,5 \times 10^{2} \mathrm{UFC} / \mathrm{cm}^{2}$, sendo estes valores superiores ao encontrado na mesma região para o atual trabalho que foi de $0,5 \times 10^{0}$ $\mathrm{UFC} / \mathrm{cm}^{2}$. Em relação à contagem de Aeromonas spp. na superfície muscular durante a fase de toalete das carcaças, o presente estudo encontrou uma popula-

\footnotetext{
*Swinnex Disc Filter - Millipore .
} 
ção de $0,5 \times 10^{0} \mathrm{UFC} / \mathrm{cm}^{2}$ na região traseira de apenas uma carcaça. Esses autores encontraram população maior que no presente estudo, entre $0,2 \times 10^{2} \mathrm{e} 3,0 \times 10^{2}$ $\mathrm{UFC} / \mathrm{cm}^{2}$ na superfície muscular da região dianteira de duas carcaças.

Dentre as amostras de superfície muscular da carcaça resfriada, foi possível realizar a contagem populacional a partir de apenas uma amostra da região traseira, com população também de $0,5 \times 10^{\circ}$ $\mathrm{UFC} / \mathrm{cm}^{2}$. Apesar de ser um valor muito pequeno, é importante ressaltar a característica psicrotrófica de algumas espécies de Aeromonas spp., o que permite que esta população possa se elevar durante o armazenamento até o momento do consumo da carne.

A contagem de Aeromonas spp. a partir da superfície do piso e ralo da câmara de resfriamento foi possível somente em três (20\%) amostras, apresentando valores de $1,2 \times 10^{0}, 3,2 \times 10^{0} \mathrm{e} 9,2 \times 10^{0} \mathrm{UFC} / \mathrm{cm}^{2}$.

Para as amostras de ambiente, a contagem foi possível em cinco delas, com populações variando de 1,0 a 3,0 $\times 10^{0} \mathrm{UFC} /$ placa, fornecendo 14 isolados. Rossi JuNIOR et al. (2006) pesquisaram a presença de Aeromonas spp. no ambiente da sala de matança e de 30 amostras, somente uma foi positiva, demonstrando que o ambiente pode atuar como possível fonte de contaminação para a carcaça. A pesar de autores como PRENDERGAST et al. (2004) não concordarem que a via aérea seja uma importante rota de contaminação das carcaças durante o abate, a pesquisa desta possível via de contaminação pelas Aeromonas spp. deve ser realizada com o intuito de se obter mais informações sobre este assunto para essa bactéria, uma vez que estes dados são escassos.

Na Tabela 1 estão apresentados os resultados relativos ao isolamento de Aeromonas spp. após o enriquecimento seletivo a partir de cada ponto de colheita, mostrando o número de amostras positivas obtidas após esta etapa e revelando a importância da realização do enriquecimento seletivo para recuperar estes micro-organismos. Observa-se que foi possível analisar 38 amostras. Observa-se ainda que, para alguns pontos, apesar do enriquecimento seletivo, não foi possível isolar a bactéria. Salienta-se que as amostras de ambiente não estão incluídas nesta tabela por não terem sido submetidas ao enriquecimento seletivo.

Em relação à amostragem das mãos, nenhuma permitiu o isolamento de Aeromonas spp. antes do início da jornada de trabalho, provavelmente porque a colheita foi realizada após a higienização das mãos com sabão, água e álcool em gel. Dentre as amostras durante a jornada de trabalho, oito $(53,3 \%)$ permitiramoisolamento da bactéria. Diferentemente, Rossi Junior etal. (2000a) encontraram Aeromonas spp. em duas (6,7\%) mãos antes doinício das atividades noabatedouroeemsete $(23,3 \%)$ amostras durante as atividades. Este fato indica a possibilidade deos manipuladores constituírem-seemfonte de contaminação da carne bovina durante o processo deabate, sugerindoa adoção demelhorianas condições higiênico-sanitárias do estabelecimento.

Tabela 1 - Número de amostras de Aeromonas spp. obtidas após o enriquecimento seletivo para cada local de colheita analisado em abatedouro bovino no interior de São Paulo, 2007.

\begin{tabular}{lc}
\hline Local de colheita & $N^{0}$ de amostras positivas após o enriquecimento seletivo \\
\hline Pele seca & 0 \\
Pele úmida/ dianteiro & 2 \\
Pele úmida/ traseiro & 3 \\
Sup. musc. dianteira/ toalete & 2 \\
Sup. musc. traseira/ toalete & 1 \\
Sup. musc. dianteira/ carc.resfr. & 2 \\
Sup. musc. traseira/ carc.resfr. & 1 \\
Mãos manipul. matança/ antes trabalho & 0 \\
Mãos manipul. matança/ durante trabalho & 8 \\
Mãos manipul./ câm. resfriamento & 0 \\
Facas & 0 \\
Parede câmara resfriamento & 0 \\
Piso e ralo câmara resfriamento & 4 \\
Água sem tratamento & 2 \\
Água tratada & 0 \\
Água residuária/ lavagem carcaças & 4 \\
Carne & 4 \\
Conteúdo intestinal & 5 \\
\hline Total & 38 \\
\hline
\end{tabular}


A pesquisa de Aeromonas spp. nas amostras de superfície do piso e ralo da câmara de resfriamento foi possível em quatro delas, sendo três obtidas das placas de contagem direta e, após o enriquecimento, uma amostra adicional permitiu o isolamento destas bactérias. Muito embora nenhuma amostra de superfície de parede estava contaminada por Aeromonas spp., a presença destas bactérias na superfície de piso e ralo adquire importância no momento da higienização da câmara, pois é realizada utilizandose água sob alta pressão. Este fator é importante porque pode ocasionar a transferência da bactéria do piso para as paredes da câmara onde, dependendo da localização, consiste em um ponto de contato da carcaça no momento em que são encaminhadas para esta sala.

Nas amostras de água residuária da lavagem das carcaças, quatro $(26,6 \%)$ destas permitiram o isolamento das Aeromonas spp. após o enriquecimento.São escassos os trabalhos na literatura científica que tenham analisado este tipo de amostragem. RossIJUNIOR et al. (2000b) avaliaram 30 amostras deágua residuária das carcaças e conseguiram isolar Aeromonas spp.em 33,3\% delas. Em um abatedouro de Porto Alegre (RS), BIZANI; BRANDELLI (2001) pesquisaram a ocorrência dessas bactérias em 35 amostras de água residuária de carcaça após a lavagem final das mesmas, isolando Aeromonas spp. de nove delas $(25,7 \%)$, sendo este um resultado próximo ao encontrado no presente estudo.

Quanto à presença das Aeromonas spp. nas amostras deágua, muitoembora ela seja considerada hábitat natural destas bactérias, somente 13,3\% das amostras de água não clorada apresentaram tais micro-organismos, evidenciado um provável número muito reduzido destes micro-organismos nessa água. Em relação à água tratada, Aeromonas spp. não foi encontrada em nenhuma das amostras; já BIZANI; BRANDELLI (2001) as detectaram em seis $(17,1 \%)$ das 35 amostras colhidas na linha de abate.

Segundo as análises de Rossi JUNIOR et al. (2000b), a água não tratada pode ser uma importante fonte de contaminação, principalmente para a pele e, através dela, as Aeromonas spp. podem chegar à sala de matança. No abatedouro onde as amostras analisadas no presente estudo foram colhidas, a água ainda não deve ser considerada um motivo de preocupação como veículo de contaminação das carcaças por essas bactérias, podendo-se enfatizar a importância da utilização do cloro para o tratamento da água utilizada na indústria.

Nas amostras de carne também não foi possível determinar a população de Aeromonas spp., contudo, após a etapa de enriquecimento, quatro amostras $(26,6 \%)$ apresentaram contaminação bacteriana. No trabalho de Rossi JunIor et al. (2006) foi possível reali- zar a contagem em apenas uma amostra de carne desossada, contudo, de 30 amostras analisadas, seis (20\%) possibilitaram o isolamento.

Em relação à presença de Aeromonas spp. no conteúdo intestinal, assim como citado por outros autores, constatou-se a dificuldade no isolamento destas bactérias no meio utilizado para semeadura direta, sendo possível somente após o enriquecimento seletivo. Após esta etapa, no presente estudo foi possível isolar a bactéria em cinco amostras, fornecendo 37 isolados. GRAY; STICKLER (1989) pesquisaram a ocorrência desses micro-organismos em 481 amostras de suabes retais de vacas e encontraram Aeromonas spp. em $4,6 \%$ dos animais. Esses autores constataram, ainda, que a maioria $(98,5 \%)$ das amostras fecais revelou a existência da bactéria apenas após o enriquecimento.

No presente estudo, a partir das amostras obtidas após o enriquecimento seletivo somadas às cinco amostras de ambiente, foi possível identificar 59 isolados como sendo $A$. caviae, um de $A$. sobria, um de $A$. trota e um de $A$. schubertii.

O isolado de $A$. sobria pertence a um dos cultivos da amostra de superfície muscular durante a fase de toalete das carcaças; o isolado de $A$. schubertii pertence a um dos cultivos provenientes de uma amostra de água residuária da lavagem das carcaças e o isolado de $A$. trota é proveniente de um dos cultivos de uma amostra de água sem tratamento. Os isolados de $A$. caviae pertencem aos demais tipos de amostras.

Dentre as espécies isoladas, a prevalência de $A$. caviae deve ser considerada relevante, pois trata-se de uma das espécies causadoras de gastroenterite em humanos e, apesar de A. sobria ter sido isolada de uma única amostra, sua presença no frigorífico não deve ser ignorada, pois consiste em uma das espécies produtoras de enterotoxinas (MARTINs et al., 2002).

Os padrões de sensibilidade dos cultivos de Aeromonas spp. conforme a espécie são apresentados na Tabela 2 onde se observa um perfil de multirresistência para vários isolados, destacandose o isolado de $A$. sobria que apresentou um comportamento de resistência a oito dos 12 princípios utilizados; o isolado de $A$. schubertii foi resistente a cinco princípios e, $A$. trota, a três; os isolados de $A$. caviae apresentaram perfis de sensibilidade variáveis.

Todos os isolados apresentaram resistência à cefalotina e ampicilina e somente um não apresentou resistência à associação de amoxicilina com clavulanato; enquanto que a totalidade dos isolados mostrou-se sensível somente em relação ao cefepime e imipenem. Oresultado em relação à ampicilina já era esperado, pois outros trabalhos encontraram resistência em 100\% de suas amostras (SHARMA et al., 2005; RADU et al., 2003) além do fato de a ampicilina ser usada como agente seletivo durante o isolamento. 
Tabela 2 - Distribuição dos isolados de Aeromonas spp. conforme seu comportamento de resistência frente à ação de antimicrobianos de amostras colhidas em abatedouro bovino no interior de São Paulo, 2007.

\begin{tabular}{lllll}
\hline Antimicrobiano & $\begin{array}{l}\text { A. caviae } \\
\mathrm{N}^{\mathrm{O}}(\%)\end{array}$ & $\begin{array}{l}\text { A. sobria } \\
\mathrm{N}^{\mathrm{o}}(\%)\end{array}$ & $\begin{array}{l}\text { A. trota } \\
\mathrm{N}^{\mathrm{o}}(\%)\end{array}$ & $\begin{array}{l}\text { A. schubertii } \\
\mathrm{N}^{\mathrm{o}}(\%)\end{array}$ \\
\hline Amicacina & $2(3,4)$ & $1(100,0)$ & $0(0,0)$ & $0(0,0)$ \\
Amoxicilina+clavulanato & $58(98,3)$ & $1(100,0)$ & $1(100,0)$ & $1(100,0)$ \\
Ampicilina & $59(100,0)$ & $1(100,0)$ & $1(100,0)$ & $1(100,0)$ \\
Cefalotina & $59(100,0)$ & $1(100,0)$ & $1(100,0)$ & $1(100,0)$ \\
Cefepime & $0(0,0)$ & $0(0,0)$ & $0(0,0)$ & $0(0,0)$ \\
Cefoxitina & $32(54,2)$ & $1(100,0)$ & $0(0,0)$ & $0(0,0)$ \\
Ceftazidima & $3(5,0)$ & $0(0,0)$ & $0(0,0)$ & $0(0,0)$ \\
Cefuroxima & $8(13,6)$ & $1(100,0)$ & $0(0,0)$ & $1(100,0)$ \\
Ciprofloxacin & $6(10,2)$ & $1(100,0)$ & $0(0,0)$ & $0(0,0)$ \\
Gentamicina & $7(11,9)$ & $0(0,0)$ & $0(0,0)$ & $0(0,0)$ \\
Imipenem & $0(0,0)$ & $0(0,0)$ & $0(0,0)$ & $0(0,0)$ \\
Sulfazotrim & $12(20,3)$ & $1(100,0)$ & $0(0,0)$ & $1(100,0)$ \\
\hline
\end{tabular}

BIZANI; BRANDELLI(2001), em um abatedouro no Rio Grande do Sul, não isolaram $A$. caviae, A. trota e $A$. schubertii de suas amostras, mas isolaram dois cultivos de A. sobria dentre 35 de água de lavagem de carcaças. Assim como no presente estudo, ambos isolados mostraram-se resistentes à ampicilina e cefalotina, além da amoxicilina e também apresentaram sensibilidade à gentamicina. Entretanto, os resultados desses autores mostraram $100 \%$ de sensibilidade à amicacina.

A sensibilidade das Aeromonas spp. a antimicrobianos foi testada por PALÚ et al. (2006), no Rio de Janeiro, em 83 amostras (28 isolados de fezes humanas e 55 de alface fresca). Similarmente ao presente estudo, todas suas amostras mostraram sensibilidade ao imipenem. Esses autores também obtiveram sensibilidade à amicacina, ciprofloxacin e gentamicina em todas suas amostras, enquanto que o presente estudo mostrou uma sensibilidade parcial a essas drogas. Nos demais antimicrobianos testados por esses autores, ocorreu grande variabilidade de perfis de resistência dentre os diferentes tipos de amostragem. Aqueles autores mostraram, ainda, que $27,6 \%$ dos isolados de alface e $42,1 \%$ dos isolados de amostras clínicas eram de $A$. caviae e mostraram-se resistentes à cefoxitina, enquanto que no presente estudo, 54,2\% dos isolados desta espécie apresentaram este perfil.

GUERRA et al. (2007) isolaramAeromonas spp.em 27 $(6,6 \%)$ de 408 pacientes acometidos de gastroenterite aguda em dois hospitais do Rio Grande do Sul, sendo A. hydrophila (51,8\%), A. caviae (40,8\%) e A.veronii biotipo sobria $(7,4 \%)$. O teste de sensibilidade a antimicrobianos, assim como no presente estudo, revelou resistência de todos os isolados para ampicilina e cefalotina além da ticarcilina/ácido clavulânico e cefazolim. Esses autores relatam que alguns isolados podem ser considerados multirresistentes, uma vez que apresentaram resistência a mais de quatro antimicrobianos.

A resistência a antimicrobianos entre os enteropatógenos consiste em um sério problema nos países em desenvolvimento onde há uma alta frequência de enfermidades gastroentéricas, sendo muitos antimicrobianos rotineiramente utilizados e deforma inadequada. A resistência é particularmente relevante nas espécies patogênicas deAeromonasspp. nas quais a multirresistência tem sido identificada (PAlú et al ., 2006; Guerra et al., 2007).

\section{CONCLUSÕES}

Muito embora a população de Aeromonas spp. determinada pela contagem direta tenha sido baixa e ocorrido em um número pequeno de amostras, o enriquecimento seletivo possibilitou a recuperação destas bactérias em um maior número de amostras indicando que, em condições inadequadas de armazenamento, as Aeromonas spp. poderiam se multiplicar e causar enfermidades no indivíduo que consumir essa carne e seus derivados. A resistência da totalidade dos isolados a determinados antimicrobianos indica que estes devem ser utilizados criteriosamente com a finalidade de evitar ao máximo o surgimento precoce de cepas deAeromonas spp. multirresistentes. Dentre as espécies envolvidas em casos de gastroenterite em humanos, foram isoladas A. caviae e A. sobria, sendo a maior prevalência da primeira. 


\section{AGRADECIMENTOS}

Os autores agradecem à Fundação de Amparo à Pesquisa do Estado de São Paulo (FAPESP) pelo suporte financeiro, à indústria onde o trabalho foi realizado pela cessão de suas instalações industriais para realização das colheitas, bem como aos funcionários da indústria pela participação e dedicação demonstradas.

\section{REFERENCIAS}

ABOTT, S.L.; CHEUNG, W.K.W.; JANDA, J.M. The genus Aeromonas: biochemical characteristics, atypical reactions, and phenotypic identification schemes. Journal of Clinical Microbiology, v.41, n.6, p.2348-2357, 2003.

ALCAIDE, E.; BLASCO, M.D.; ESTEVE, C. Mechanisms of quinolone resistance in Aeromonas species isolated from humans, water and eels. Research in Microbiology, v.161, p.40-45, 2010.

BIZANI, D.; BRANDELLI, A. Antimicrobial susceptibility, hemolysis, and hemagglutination among Aeromonas spp. Isolated from water of a bovine abattoir. Brazilian Journal of Microbiology, v.32, p.334-339, 2001.

DASKALOV, $\mathrm{H}$. The importance of Aeromonas hydrophila in food safety. Food Control, v.17, p.474-483, 2006.

DOHERTY, A.; SHERIDAN, J.J.; ALLEN, P.; McDOWELL, D.A.; BLAIR, I.S.; HARRINGTON, D. Survival and growth of Aeromonas hydrophila on modified atmosphere packaged normal and high $\mathrm{pH}$ lamb. International Journal of Food Microbiology, v.28, p.379-392, 1996.

FURUWATARI, C.; KAWAKAMI, Y.; AKAHANE, T.; HIDAKA, E.; OKIMURA, Y.; NAKAYAMA, J.; FURIHATA, K.; KATSUYAMA, T. Proposal for an Aeroschem (modified Aerokey II) for the identification of clinical Aeromonas species. Medical Science Research, v.22, p.617-619, 1994.

GILL, C.O.; REICHEL, M.P. Growth of the cold-tolerant pathogens Yersinia enterocolitica, Aeromonas hydrophila and Listeria monocytogenes on high-pH beef packaged under vacuum or carbon dioxide. Food Microbiology, v.6, p.223-230, 1989.

GRAVAENITZ, A. von. The role of Aeromonas in diarrhea: a review. Infection, v.35, n.2, p.59-64, 2007.

GRAY, S.J.; STICKLER, D.J. Some observations on hte faecal carriage of mesophilic Aeromonas species in cows and pigs. Epidemiology and Infection, v.193, p.523-537, 1989.
GUERRA, I.M.F.; FADANELLI, R.; FIGUEIRÓ, M.; SCHREINER, F.; DELAMARE, A.P.L.; WOLLHEIM, C.; COSTA, S.O.P.; ECHEVERRIGARAY, S. Aeromonas associated diarrhoeal disease in South Brazil: prevalence, virulence factors and antimicrobial resistance. Brazilian Journal of Microbiology, v.38, p.638643, 2007.

HAVELAAR, A.H.; VONK, M. The preparation of ampicillin dextrin agar for the enumeration of Aeromonas in water. Letters in Applied Microbiology, v.7, p.169-171, 1988.

HUDSON, J.A.; MOTT, S.J.; PENNEY, N. Growth of Listeria monocytogenes, Aeromonas hydrophila and Yersinia enterocolitica on vacuum and saturated carbon dioxide controlled atmosphere-packaged sliced roast beef. Journal of Food Protection, v.57, p.204-208, 1994.

KIROV, S.M. Food microbiology: fundamentals and frontiers. In: DOYLE, M.P.; BEUCHAT, L.R.; MONTVILLE, T.J. (Ed.). Aeromonas and Plesiomonas Species. Washington: ASM Press, 1997. p.265-287.

KIROV, S.M.; BRODRIBB, F. Exotoxin production by Aeromonas spp. in foods. Letters in Applied Microbiology, v.17, p.208-211, 1993.

LAACK, R.L.J.M. van; JOHNSON, J.L.; PALEN, C.J.N.M.; van der S, SMULDERS, F.J.M.; SNIJDERS, J.M.A. Survival of pathogenic bacteria on pork lions as influenced by hot processing and packaging. Journal of Food Protection, v.56, p.847-851, 1993.

MARTINS, L.M.; MARQUEZ, R.F.; YANO, T. Incidence of toxic Aeromonas isolated from food and human infection. FEMS Immunology and Medical Microbiology, v.32, p.237-242, 2002.

MERINO, S.; RUBIRES, X.; KNOCHEL, S.; THOMAS, J. Emerging pathogens: Aeromonas spp. International Journal of Food Microbiology, v.28, p.157-168, 1995.

NATIONAL COMMITTEE FOR CLINICAL LABORATORY STUDIES. Performance standards for antimicrobial disk susceptibility tests. 4. ed. Vilanova: NCCLS, 1990. (NCCLS document M2-A4).

PALÚ, A.P.; GOMES, L.M.; MIGUEL, M.A.L.; BALASSIANO, I.T.; QUEIROZ, M.L.P.; FREITASALMEIDA, A.C.; OLIVEIRA, S.S. Antimicrobial resistance in food and clinical Aeromonas isolates. Food Microbiology, v.23, p.504-509, 2006.

PALUMBO, S.A.; MAXINO, F.; WILLIAMS, A.C.; BUCHANAN, R.L.; THAYER, D.W. Starch-ampicillin agar for the quantitative detection of Aeromonas hydrophila. Applied and Environmental Microbiology, v.50, p.1027-1030, 1985. 
POPOFF, M. Genus III Aeromonas. In: DRIEG, N. R. (Ed.). Bergey's manual of systematic bacteriology. Baltimore: Williams \& Wilkins, 1984. p.545-548.

PRENDERGAST, D.M.; DALY, D.J.; SHERIDAN, J.J.; McDOWELL, D.A.; BLAIR, I.S. The effect of abattoir design on aerial contamination levels and the relationship between aerial and carcass contamination levels in two Irish beef abattoirs. Food Microbiology, v.21, p.589-596, 2004.

RADU, S.; AHMAD, N.; LING, F.H.; REEZAL, A. Prevalence and resistance to antibiotics for Aeromonas species from retail fish in Malaysia. International Journal of Food Microbiology, v.81, p. 261-266, 2003.

ROSSI JUNIOR , O.D.; NADER FILHO, A.; AMARAL, L.A.; SCHOCKEN-ITURRINO, R. P. Isolamento de bactérias do gênero Aeromonas da superfície das mãos de manipuladores de carne bovina, em matadourofrigorífico do estado de São Paulo. Higiene Alimentar, v.11, n.78/79, p.90-94, 2000a.

ROSSI JUNIOR, O.D.; AMARAL, L.A.; NADER FILHO, A. Bactérias do gênero Aeromonas em água de matadouro bovino. Arquivo Brasileiro de Medicina Veterinária e Zootecnia, v.52, n.5, p.549-553, 2000b.

ROSSI JUNIOR, O. D.; AMARAL, L. A.; NADER FILHO, A; SCHOCKEN-ITURRINO, R.P. Bacteria of the genus
Aeromonas in different locations throughout the process line of beef slaughtering. Revista Portuguesa de Ciências Veterinárias, v.101, n. 557-558, p.125-129, 2006.

SAAD, S.M.I.; IARIA, S.T.; FURLANETTO, S.M.P. Motile Aeromonas spp in retail vegetables from São Paulo, Brazil. Revista de Microbiologia, v.26, n.1, p.22-27, 1995.

SHARMA, A.; DUBEY, N.; SHARAN, B.

Characterization of aeromonads isolated from the river Narmada, India. International Journal of Hygiene Environmental Health, v.208, p. 425-433, 2005.

SUBASHKUMAR, R.; THAYUMANAVAN, T.; VIVEKANANDHAN, G.;

LAKSHMANAPERUMALSAMY, P. Occurrence of Aeromonas hydrophila in acute gasteroenteritis among among children. Indian Journal of Medical Research, v.123, p.61-66, 2006.

ULLMANN, D.; KRAUSE, G.; KNABNER, D.; WEBER, H.; BEUTIN, L. Isolation and characterization of potentially human pathogenic, cytotoxin-producing Aeromonas strains from retailed seafood in Berlin, Germany. Journal of Veterinary Medicine. Series B, v.52, p.82-87, 2005.

Recebido em 13/10/08

Aceito em $7 / 6 / 10$ 